\title{
Mentoring and Individual Learning Plans: issues of practice in a period of transition
}

\begin{abstract}
This paper draws upon research undertaken with 28 teacher education mentors, managers and trainee teachers within the SW Centre for Excellence in Teacher Training (CETT) in 2008, following the introduction of the new Lifelong Learning UK (LLUK) standards. The first part of the paper locates and contextualises the policy context in relation to the school and further education (FE) sectors. Two separate and distinctive models of mentoring practice are delineated, the first model as a source of formative support for the learning of trainee teachers, and the second model as a tool for the assessment of competence. The paper concludes by suggesting that the danger and indeed unintended consequence of separating out these functions of mentoring is that an unnecessary dichotomy is created that dislocates once coherent teacher practices from one another. It argues that what is needed is a sustained period of stability in the sector. This would leave a space for CETT professionals and others to promote those practices that will make a difference not only to the work of teacher educators but to the work of staff and students.
\end{abstract}




\section{Introduction}

The further education (FE) sector in the UK has seen a reform of teacher training with the introduction of qualifications designed to meet the professional needs of individuals who operate in different contexts. The assumption is that 'standards' and teacher performance can be improved through the introduction of tighter and more prescribed controls of the processes of teacher education with an emphasis on subject specific approaches. This was articulated in an early survey report from the Office for Standards in Education (Ofsted 2003 see also Ofsted 2006; 2007; 2008 ).

The current system of FE teacher training does not provide a satisfactory foundation of professional development for FE teachers at the start of their careers. While the tuition that trainees receive on the taught elements of their courses is generally good, few opportunities are provided for trainees to learn how to teach their specialist subjects, and there is a lack of systematic mentoring and support in the workplace. (Ofsted 2003, 2)

The publication of the White Paper, Further education: raising skills, improving life chances (DfES 2006) culminated in a set of revised standards (LLUK 2007a; 2007b) that were tighter and more prescriptive than the Further Education National Training Organisation (FENTO) standards that preceded them (FENTO 1999). This was followed by a plethora of National Awarding Body (NAB) qualifications, from Preparing to Teach in the Lifelong Learning Sector (PTTLS) to the Diploma in Teaching in the Lifelong Learning Sector (DTTLS) through M-level university accredited Postgraduate Certificate qualifications (PGCE), which differentiated the market for qualifications at entry. 
One of the main characteristics of the workforce in the FE sector is that the majority of those undertaking training work in a part-time capacity within vocational areas where degree level qualifications are not a pre-requisite for entry into the profession (for example, catering and hairdressing). Such differences contrast with the more straightforward situation in the compulsory (school) sector where graduate teachers are required to undertake a programme of certified and accredited training prior to taking up their employment (see Orr, 2009; Nasta, 2007). Since 2001 there has been a statutory requirement for all teachers in the FE sector to undertake a formal teacher training programme that is appropriate to their role. The requirement has been for the training to include initial assessment, accreditation of prior learning, skills support, mentoring, blended learning, observation; a progress log, and registration with the Institute for Learning (IfL) - the body responsible for the professional formation of teachers that governs the licence to practice in relation to the Lifelong Learning UK (LLUK) standards.

Whilst many 'post-92' universities have accommodated and even embraced the changes within the sector, some universities validating and/or delivering these qualifications made use of the opportunity to review their post compulsory teacher training programmes. There are various reasons for this, however the one that stands out is the shift to gradings where judgements from the Ofsted are now made at an institutional level rather than at a programme level, exposing the provision to increased internal scrutiny. For some teacher training providers the increased control, surveillance and external accountability over 'messy' FE sector provision was perceived as a threat to the gradings achieved in their mainstream school provision. These issues were emphasised in some programmes more than others, where staff, who had been accustomed to greater autonomy of practice, found it difficult, or were unwilling, to adapt to the new structure and systems (Lawy and Tedder 2009a). 
In the summer of 2007 the SWitch CETT invited its members to submit proposals for a series of projects related to the changing regulations governing professional qualifications. This paper relates to two linked research projects concerning Individual Learning Plans (ILPs) and the training of mentors, and was undertaken in the year where the programme was experiencing profound change to reflect the requirements from Ofsted. The aim of the research project was to represent the relationship between the mentoring function and the use of ILPs (Lawy and Tedder, 2009b) - to identify and model exemplars of 'best practice' and make suggestions for future practice and engagement. Although the predominant emphasis was upon mentoring and ILPs and their use in teacher education, the literature review for the project encompassed exemplars drawn from a variety of work-based sources.

Until relatively recently, mentoring and specific curriculum support for trainee teachers tended to be provided in the staffroom by colleagues on an ad hoc and informal basis. It was rarely linked formally to college systems and structures including teacher training programmes. Responsibility for pastoral and other matters relating to trainee teachers was assigned to teacher education teams who undertook these responsibilities as part of their professional commitment to their students. The idea of extending the responsibility outwards from the core team to subject mentors and coaches is a relatively new innovation with government reforms emphasising subject specific mentor and ILP engagements (see e.g. Ofsted 2003; DfES 2006) This focus derives largely from secondary school practice where teacher training has continued to be organised within subject disciplinary frameworks rather than as a set of common pedagogical practices. Commenting in a text for trainee teachers Keeley-Browne (2007) explains:

As part of your training you will be allocated to a mentor, or learning coach, who will advise you on the general skills of training to teach. Your mentor will be skilled in 
what is called the pedagogy of the classroom. You will also be given access to a subject specialist coach (this may be the same person as your mentor/learning coach) who will help you develop the skills that are specific to your areas of the curriculum. (Keeley-Browne 2007, 9)

But such approaches are not accepted universally, and there are adult educationalists amongst others who argue that specific subject knowledge and pedagogies do not comprise discrete and separate disciplinary constructions (see e.g. Young 1998; Usher et al. 1997). Within this schema, mentoring and ILPs are not linked to the achievement of a set of agreed and identifiable outcomes that are instrumental in their orientation (see Stenhouse 1975) but are linked to a set of much broader, less prescriptive developmental outcomes.

Following this introduction the paper is split into four sections. In the next section the methods of the research are discussed. This is followed by a section that examines some of the literature concerning the core conceptual issues that are being investigated. The findings section is split into two parts. In the first part we explore the interviewees' views and understandings of mentoring and in the second part we explore their views and understandings of ILPs. The final section comprises a general discussion of the issues and some conclusions. The key claim of the paper is that there is a lack of clarity about the purpose and role of mentoring either as a source of formative support or, where it is linked to the use of ILPs, as a tool for the assessment of competence.

\section{Methods}

The project was designed to be qualitative and interpretative in order to enable interviewees to go beyond answering narrowly technical questions about mentoring and ILP practices and processes. What we were seeking was a deeper understanding that would convey something 
of the relation between prior experience and understandings and professional formation. The aim was to explore this as process and practice. We wanted to collect stories about experiences both inside and outside of formal education in a way that is detailed and richly textured.

To make refined judgements about what educational action to take in particular cases lodged in particular contexts, we need much more information than can at present be reduced to indices and we need to present our conclusions in a way that feeds the judgement of the actors in the situation, a way that educates them rather than briefs them. (Stenhouse 1980, 3)

28 semi-structured interviews were conducted in the early months of 2008 with mentors, trainee teachers and managers in the field of FE teacher education. The interviews lasted anywhere between 45 minutes and two hours and enabled the research team to collect rich qualitative data from ten trainees, from nine teacher educators who fulfil roles as tutors and/or mentors in programmes and also from nine managers. The interviews were distributed as follows:

\section{Table 1}

Interviewee places of work and training

\begin{tabular}{|l|l|l|l|}
\hline & Managers & Mentors & Trainees \\
\hline FE Colleges & 5 & 7 & 7 \\
\hline LEA Adult Education & 2 & 2 & \\
\hline Voluntary sector & 1 & & 1 \\
\hline Private sector & 1 & & 2 \\
\hline & & & 10 \\
TOTAL & 9 & 9 & \\
\hline
\end{tabular}

Four of the trainees were enrolled on PGCE and Cert. Ed. Programmes, three were on Certificate in Teaching in the Lifelong Learning Sector (CTTLS) and Diploma in Teaching in the Lifelong Learning Sector (DTTLS). The remainder were on an introductory, Preparing to 
Teach in the Lifelong Learning Sector (PTTLS) programme. Two of the trainees were on fulltime courses. Seven of the nine mentors were college based with two employed separately in Adult Education. All of the nine managers had some role in either managing and/or teaching on teacher education programmes and were variously employed in different institutions.

Each interview began with an explanation of the ethical protocols and the interviewees were asked to sign a consent form. This explained that the research data would be treated as confidential and that they had the right to withdraw at any stage. All the respondents were offered the opportunity to check the accuracy of the transcripts from their interviews and withdraw from the research process at any stage, including use of any data pertaining to them. The initial questions were largely descriptive with the interviewees asked to describe themselves and their position and engagement in their organisations - all of which provided important contextual information and allowed the respondents to feel at ease. Later questions were more probing and included such prompts as 'What did you do?'; 'Can you give me an example of ... ?'; What sense did you make of this experience?' The questions were deliberately open-ended allowing for a deeper exploration and understanding than would have been possible using closed questions. This approach was designed to go beyond narrowly technical questions about mentoring practices and capture something of what mentoring had meant for our interviewees in their personal and professional development.

All the interviews were fully transcribed, analysed and coded in a manner that allowed us to develop our conceptual frameworks and understandings rather than imposing our presuppositions upon the data (Strauss and Corbin 1990). Whilst we wanted to reflect the interests and engagements of the interviewees we were also concerned in our analysis to move one step beyond their interpretations to understand underlying issues and causes. During the analysis phase we made use of opportunities that were available to us through our links with 
the Centre for Excellence in Teacher Training (CETT) and through seminar presentations at national and international conferences to share our interpretations of the data with other teacher training professionals.

\section{Mentoring and Coaching - problems of definition and meaning}

During the early phase of the research various approaches to mentor practice and the use of ILPs within the public and private sectors were explored via a literature search. These comprised models of practice from the private and public sectors, including work-based (e.g. Balfour Beatty and Deutsche Bank) and educational contexts (Birmingham Adult Education Service [BAES] and the Training and Development Agency [TDA]) as well as mentoring schemes from professional associations such as the European Mentoring and Couching Council (EMCC) and the Chartered Institute of Personnel and Development (CIPD). All of the organisations that were explored were committed to the idea of mentoring but it was clear that different definitions and models of mentoring were in use. Given such differences of understanding, there is the potential for confusion between them. Conscious of this the CIPD provide a clear explanation of different functions in mentoring schemes.

The CIPD is a professional body with 135,000 individual members. Its published mission is to lead in the development and promotion of good practice in the field of the management and development of people. The CIPD was interesting because it clearly articulates what it sees as the most important source of confusion between mentoring and coaching (CIPD, 2010). The CIPD note that mentoring is separate and distinct from coaching, but that coaching and mentoring can often overlap. It sees coaching as:

developing a person's skills and knowledge so that their job performance improves, hopefully leading to the achievement of organisational objectives. It targets high 
performance and improvement at work, although it may also have an impact on an individual's private life. It usually lasts for a short period and focuses on specific skills and goals. (CIPD 2010)

Mentoring is seen as operating on as a three stage process, of exploration, of new understanding, and of action planning (see Alred et al. 1998). It is a supportive process of learning and development that is more informal than coaching and helps individuals to manage their career by improving their skills and addressing personal issues. It enables people to identify and take action to achieve both organisational and individual goals with the agenda set by the mentee. As such, it is primarily about developing capability and potential rather than performance and skills.

The problems of definition and understanding and the implications arising from them that are identified here, were very evident in our interviews. As is indicated in the next section, many were unsure about their roles and responsibilities as mentors and mentees, operating in many instances with conflicting understandings of mentor and coach.

\section{Findings}

This section has been split into two separate but linked parts. In the first part we discuss issues of mentoring in relation to all of our cohort and in the second part we discuss questions pertaining to ILPs. This structure was deliberately chosen rather than one that separates out the views of managers and mentors and trainee teachers.

\section{Mentoring}

Within the group of ten trainees, four had mentors with whom they had established a good personal relationship and the mentor was judged to make a valued contribution to the trainee's personal and professional development; three trainees did not value their mentor's contribution, though for differing reasons. Prior to entry to the PGCE programme as a trainee 
teacher, Edward led a successful career in engineering and management that included coaching and mentoring staff; he made no distinction between the two processes but expected a systematic approach that would be led by the recipient:

Whenever I've coached or mentored people I've always gone deep, let them get to point where they don't know something, they're not sure of something, a contradiction or, you know, ignorance, 'I don't know what you're talking about.' 'Stop, make a note, that's your objective for the next one. I want to know what that means and you're going to explain it to me and you have a week to do so. Okay? Right, do you want to carry on or do you want to stop?'

Edward was not impressed by the subject expert who was appointed as his mentor but not all the trainee teachers were so critical. Indeed, seven of the ten trainees expressed their appreciation of colleagues who were supportive of their professional development. In fact, the interviews revealed a complex network of different kinds of support, with some formal mentor arrangements made by course providers and some informal, usually work-based support, with arrangements made by the trainee. Another trainee, Graham, explained:

Well, they've got to be accessible. If you've got a mentor that you can't get hold of it's a very difficult thing. So I'm guessing to be nice but to be honest and straight down the line so you know what you're expected, obviously they can't be a scary person because you wouldn't feel comfortable... I guess that the biggest thing that I'd have to say from [tutor name] is that she's really, really passionate about teaching and I'm guessing that a mentor has to be passionate about what they do. 
Mentors and managers tended to assert the quality of relationship between mentor and mentee as a crucial factor in teacher education. They reported a range of ways in which mentoring support for professional formation can occur very successfully informally (for example, in 'buddy' arrangements) and also in formal systems (led by team leaders within course meetings) even though such experiences may not be termed 'mentoring'. They also pointed to systems and structures, for example 'advanced practitioner/teachers' and 'subject learning coaches', that fulfil similar or complementary functions in some colleges. It was clear that there were differences of understanding about mentoring underpinning such variety of practice and the managers we interviewed were not exempt from articulating the differences. Andrew, for example, was keen that advanced teachers in his college should be regular members of the teacher training team:

We want an [advanced teacher] to be able to generalise their own experiences of being expert at their subject, to be able to take it to others in development sessions, in mentoring, in observations across the college and in working with the, with the teacher education team.

For Angela, however, there needed to be a clear distinction between the teacher education and mentoring roles:

Our best practitioners .... weren't there to simply demonstrate how good they are at teaching science or hairdressing or history ... their core subjects. They were there to teach this other curriculum.

References were made to the need for mentors to establish a friendly but professional relationship with their mentees with clear boundaries that should be separate from a role of 
assessing performance to satisfy requirements for surveillance and formalised judgementmaking. As Gill explained:

[Mentoring] is about challenging. It's not about being a friend. It's not about placating people and saying, 'Yes you're wonderful and you know, how can I help?' It's about challenging... and about being critical and being, you know, 'Have you thought about, what do you mean by that?' ... Opening doors but not pushing people through them.

The trainee teachers were conscious of the need to work collegially within their subject teams. For example, Naomi explained how she was also able to draw upon advice and support from colleagues other than her mentor, who was also her line manager:

We have somebody in the office who's actually a college, ex-college lecturer tutor, in fact there's two people, and so they're very good. So if it's to do with college, and we're a bit sort of unclear about something, we usually talk to them.

\section{Individual Learning Plans}

The idea of an ILP are formal document or diary of change and practice is closely allied to the particular performative model of mentoring that has been introduced into the FE sector (Lawy and Tedder in press). Indeed, we found that many of the issues or problems of practice relating to mentoring and ILPs were shared in common and that when they were different they could not be attributed to a particular group. There was consensus from the tutors, mentors and managers of the need for trainee teachers to understand and be able to use ILPs in their day-to-day practices as teachers. ILPs have become established, particularly in certain fields of training (including NVQ programmes, Modern Apprenticeship, and in Skills for Life) where there are commonly well-documented statements of learning outcomes. However, this 
did not mean that the tutors, mentors and managers that were interviewed were happy with the way ILPs had been appropriated and modelled into their teacher education programmes. All were familiar with broad principles of producing ILPs with trainees (such as undertaking initial assessment, SWOT analysis, action planning, target setting etc) and the standards that underpin them. However, they varied in how much importance they attached to these processes and many were not fully committed to these demands. One tutor, Maggie, drew attention to the difference between the scheme that existed on paper and her actual practice with trainees:

If I'm honest, I didn't really look at the standards at all, I was looking at the ILP itself and referring it back to the individuals... where people were stuck then having general discussions about it and, you know, kind of prompting thoughts with other people.

Some mentors such as Christopher felt that ILPs could be a useful tool. However, he considered trainees were 'filling out' their ILP forms and was not at all sure they were 'using' them in the way that was intended. He doubted that there was sufficient follow-up to the plans and reviews of progress for the ILPs to become meaningful or related to their actual teaching.

The trainee teachers usually recognised the importance in the programme of their ILPs but many did so in a functional way. None saw the documents as anything other than a record to enable supervision and assessment by their mentors. ILPs were seen very much as a mechanism for recording and monitoring the formalised discussions and achievements that had taken place in the formal mentoring meetings between trainees and their mentors rather than the representation of a confidential dialogic discourse. There was frustration that this process was essentially bureaucratic and at least partially removed from the practical concerns of the trainees as developing teachers. They were largely concerned with 'doing the 
necessary' in the here and now to meet the formal requirements needed to complete his ILP. As Ian explained:

I think the, the value of [the standards] will perhaps kick in, you know, as everything else becomes more normal. At the moment, you know, I'm thinking all the time of the lesson plans, scheme of work, etcetera, etcetera. I've got to do this and once that becomes done, then you know, perhaps pay more attention and focus to the standards.

Kate, a part-time PGCE trainee with experience in the field of arts and textiles, worked in a large college where all new staff are allocated a mentor on induction and where mentoring has been embedded as part of the teacher education programme. Nonetheless she had little commitment to her ILP.

I think ILPs are a funny thing anyway. I think they're ultimately a bit of a waste of time, but I kind of - I know why we have to do them. It's all to do with getting money... we haven't done hardly anything 'cos I think my mentor thinks they're a bit of a waste of time as well.

The sceptical attitude of her mentor appeared to be part of a wider staffroom culture where staff seemed to value the mentor role but were less impressed with the ILP paper trail that had become part of the system. As Kate explained:

This attitude may have come from other people saying, 'Oh load of rubbish'. You know, I work in a, I work in a staffroom, I hear people talking about stuff, 'Blah, blah, blah, bloody ILPs' whatever. 
In other cases where mentoring was not embedded into the cultural fabric of the institution in the same way, there appeared to less antagonism towards the introduction of the ILPs and the processes and systems associated with them.

\section{Discussion and Conclusions}

There was clear evidence in the data of considerable confusion and uncertainty about the role of mentoring and of ILPs in support of that role. The data highlighted the contradictions between the formative and performative purposes of different models of mentoring - whether the emphasis is upon support for the learning and professional development of the trainee teacher, or whether the aim is upon assessment and the decision to award a qualification and a licence to practice in the sector. This tension has resulted in a continuous struggle as managers and mentors find the boundaries of their responsibilities, which in turn has placed the trainee teachers in an unenviable position.

Is a mentor role akin to that of a 'subject coach' or assessor who is solely responsible for the achievement of standards and for the assessment of those standards against fixed criteria? Is an ILP a document of record or a personal development journal or $\log$ ? Can it be both ? These tensions are expressed in Mentoring Towards Excellence (Association of Colleges [AoC] and FENTO 2001), and Equipping our Teachers for the Future (DfES 2004). What is interesting is the shift in rhetoric, in such a short period of time, from an approach that was essentially developmental to an iteration that is essentially judgemental and focused on assessment. As Colley (2003) suggests, the formative model finds expression in a dyadic relation between mentor and mentee. By way of contrast, the performative model brings a third party into the 
equation where a third party becomes involved in a now triadic relation. The implications are expressed below in Table 2 .

$\underline{\text { Table } 2}$

\section{Formative and performative models of mentoring}

(adapted from Tedder and Lawy 2009, 426)

\begin{tabular}{|l|l|}
\hline $\begin{array}{l}\text { Formative model (Exemplified in } \\
\text { Mentoring towards excellence) }\end{array}$ & $\begin{array}{l}\text { Performative model (Exemplified in } \\
\text { Equipping our teachers for the future) }\end{array}$ \\
\hline $\begin{array}{l}\text { Best undertaken in confidence } \\
\text { Focussed on personal and professional } \\
\text { development }\end{array}$ & $\begin{array}{l}\text { Necessarily public } \\
\text { Fupportive through transitions } \\
\begin{array}{l}\text { Frofession - centred } \\
\text { Suitable for all }\end{array}\end{array}$ \\
$\begin{array}{l}\text { Emphasis on networks } \\
\text { Led by mentee }\end{array}$ & $\begin{array}{l}\text { Concerned with standards } \\
\text { Subject - centred } \\
\text { Mainly for trainees }\end{array}$ \\
\hline
\end{tabular}

The performative model described above was largely imposed onto the FE sector by the government with little discussion of the many possible reasons for its introduction other than the argument that it had led to improved standards in the school sector. The assumption was that there was bad teaching and poor assessment of new and trainee teachers, and that more control over the process of training was required to ensure 'world class' standards. There was no recognition of the poor pay and long hours of lecturers compared with those of their colleagues in the school sector (e.g. UCU 2007). Nor was there any serious discussion of the ramifications on the culture of sector where trainee teachers continue to be taught in single rather than subject specialist groupings, commonly on an in-service part-time basis, and where course tutors have a substantial teaching responsibility that has been closely allied to a non-subject specific mentoring function.

One of the conclusions that we were able to draw from our literature review of research outside of the FE sector is that there is no 'best practice' model for mentoring. However, four distinctive aspects or facets of mentoring were identified. These comprised; a) subject 
pedagogical/specific mentoring; b) mentoring for induction into an organisation; c) mentoring to become part of a community of practice, and; d) mentoring for personal development. Whilst the research suggests that trainee teachers should be supported within their subject specialisms the research also establishes the importance of mentoring for personal, social and more general pedagogical development. The problem is that this role is not properly recognised in the current system. Indeed, there is some evidence that the focus upon subject pedagogical/specific mentoring is undermining the traditional role and function of the teacher education tutor (Lawy and Tedder 2009a). The involvement of mentors from outside of teacher education has, it is argued, reduced the opportunities for student teachers to engage in a critical exploration of pedagogical challenges within and across subject boundaries. This has been particularly evident as the mentoring and ILP processes have become bureaucratic and paper-based. Although FE colleges and universities now routinely offer training packages to erstwhile mentors that address the LLUK standards and requirements, there is a paucity of evidence of mentors being provided with a broader induction into mentoring with a specific induction into their own teacher education programmes.

There can be little doubt that in the foreseeable future mentoring and ILPs will become evermore embedded within the fabric of FE teacher education practice. Yet the expectations associated with these practices remain unclear, with the danger that mentoring practices become reduced to a performative skill-set rather than a process where trainee teachers can benefit from a deep pedagogical engagement in practice. The danger and indeed unintended consequence of separating out these different functions is that an unnecessary dichotomy is created that dislocates once coherent teacher practices from one another. This leads to the final point; one of the key issues in the FE sector over the last few years has been the continuous turbulence caused by one new initiative after another: 
The sector suffers from too much centrally driven change, too many initiatives, and too many policies. This creates instability for learners and for institutions. The pace of change and the proliferation of initiatives have been intense, and changes to targets, funding rules and paperwork have diverted staff attention away from the central task of teaching. (Teaching and Learning Research Programme [TLRP] 2007)

Coffield (2007) and Spours et al. (2007) have long argued for a sustained period of stability, allowing an opportunity for reflection and consolidation. Edward et al. $(2007,169)$ point to high staff turnover compared with their counterparts in the school sector, 'and their lack of involvement in the formation and evaluation of changes'. In terms of teacher education practice, a period of stability would allow the CETTs to consolidate their position and enable dialogue among colleagues across FE sector teacher training to explore practices and perceptions in relation to developments such as ILPs and mentoring. This would lead to greater clarity about the purposes of mentoring, the responsibilities associated with it, and to the sharing of good practice. Such an approach, that was grounded and developed in and through the sector, could really make a difference not only to the work of teacher educators but to the work of staff and students. 


\section{References}

Alred, G., B. Garvey, and R. Smith. 1998. Mentoring pocketbook. Alresford: Management Pocketbooks.

AoC and FENTO (Association of Colleges and the Further Education National Training Organisation). 2001. Mentoring towards excellence. Coventry: Learning and Skills Council.

CIPD (Chartered Institute of Personnel and Development) 2010.

http://www.cipd.co.uk/subjects/lrnanddev/coachmntor/coaching.htm Accessed 16 June 2010.

Coffield, F. 2007. Running ever faster down the wrong road: An alternative future for education and skills'. London: Institute of Education. http://www.s7colleges.com/learninginnovation/_pdf/FrankCoffieldInauguralLectureDec06\%20_3_.pdf Accessed 5 July 2010

Colley, H. 2003. Mentoring for social inclusion: A critical Approach to nurturing mentor relationships. London: Routledge.

DfES (Department for Education and Skills). 2004. Equipping our teachers for the future: Reforming initial teacher training for the learning and skills sector. London: DfES.

DfES (Department for Education and Skills). 2006. Further education: Raising skills, improving life chances. Norwich: The Stationery Office. 
Edward, S., F. Coffield., R.Steer, and M.Gregson. 2007. Endless change in the learning and skills sector: The impact on teaching staff . Journal of Vocational Education and Training 59, no. 2: $155-173$.

FENTO (Further Education National Training Organisation). 1999. Standards for teaching and supporting learning in further education in England and Wales. London: FENTO.

Lawy, R., and M. Tedder. 2009a. Meeting standards: Teacher education in the Further education sector. What of the agency of teacher educators?' Studies in the Education of Adults 41, no. 1: 53-67.

Lawy, R., and M. Tedder. 2009b. Further education initial teacher education in the learning and skills sector in the SW of England: ILPs, mentors and mentor training. Exeter: University of Exeter and SWitch CETT.

Lawy, R., and M. Tedder. in press. Beyond compliance: Teacher education practice in a performative framework. Research Papers in Education

LLUK (Lifelong Learning UK). 2007a. Further education workforce reforms, explaining initial teacher training, continuing professional development and Principals' qualifications in England. London: Lifelong Learning UK.

LLUK (Lifelong Learning UK). 2007b. Teachers, tutors and trainers in the further education (FE) Sector in England - guidance for awarding Institutions on teacher roles and initial teaching. London: Lifelong Learning UK. 
Nasta, T. 2007. Translating national standards into practice for the initial training of further education (FE) teachers in England Research in Post-compulsory Education 12, no. $1: 1-17$.

Ofsted (Office for Standards in Education). 2003. The initial training of further education teachers: A survey. London: Ofsted.

Ofsted (Office for Standards in Education). 2006. The initial training of further education teachers: Findings from 2004/05 inspection of courses leading to national awarding body qualifications. London: Ofsted.

Ofsted (Office for Standards in Education). 2007. The initial training of further education teachers. London: Ofsted.

Ofsted (Office for Standards in Education). 2008. The Initial Training of Further Education Teachers. London: Ofsted.

Orr, K. 2009. Dual roles and dual identities: Enhancing the experience of in-service teacher training in English further education. Teaching in Lifelong Learning 1, no. 2: 5-13.

Spours, K., F. Coffield, and M. Gregson. 2007. Mediation, translation and local ecologies: Understanding the impact of policy levers on FE colleges, Journal of Vocational Education and Training 59, no. 2: 193-211.

Strauss, A., and J. Corbin. 1990. Basics of qualitative research: Grounded theory processes and techniques. London: Sage. 
Stenhouse, L. 1975. An introduction to curriculum research and development. Oxford: Heinemann.

Stenhouse, L. 1980. The study of samples and the study of cases. British Educational Research Journal 6, no. 1: 1-16.

TLRP (Teaching and Learning Research programme). 2007. Research Briefing No 28: Policy, learning and inclusion in the learning and skills sector. London: Institute of Education.

Tedder, M., and R. Lawy. 2009. The pursuit of 'excellence': Mentoring in FE initial teacher training. Journal of Vocational Education and Training 61, no 4:. 413-429.

UCU (University and College Union). 2007. High stress levels in colleges and universities .'caused by management culture.' http://www.ucu.org.uk/index.cfm?articleid=2325 Accessed 7 April 2011.

Usher, R., I. Bryant. and R. Johnston. 1997. Adult education and the postmodern challenge: Learning beyond the limits. London: Routledge

Young, M. F. D. 1998. The curriculum of the future: From the 'new sociology of education' to a critical theory of learning. London: Falmer Press. 
